\title{
Levels of processing in disruptive effects of prior information
}

\author{
W. TRAMMELL NEILL \\ University of South Florida, Tampa, Florida
}

\begin{abstract}
Under certain conditions, advance information about possible letter alternatives may depress recognition of single tachistoscopically presented letters followed by a pattern mask. Neill and Walling (1981) found that this "before-disruption effect" occurred specifically when alternatives were featurally similar. In contrast, Experiment 1 of the present study found that precuing facilitated identification of unfamiliar stimuli composed of letterlike features, particularly when alternatives differed in only one critical feature. Contrary to Smith, Haviland, Reder, Brownell, and Adams (1976), composition of letterlike features is therefore not sufficient to produce the before-disruption effect. The before-disruption effect appears to occur when there is opportunity to represent the stimulus at a deeper (i.e., name) level, but foreknowledge of a critical distinguishing feature biases processing instead toward the level of physical features. Congruent with this analysis, Experiment 2 found the before-disruption effect for letters to be attenuated when targets were unpredictably upper- and lowercase, necessitating name-level matching to the alternatives. Experiment 3 found the superior identification of unprecued letters to be paradoxically associated with inferior target detection, as indicated by concurrent presence/absence judgments. In addition, identification of unprecued letters, but not precued letters, was significantly above chance on trials in which overt target detection failed to occur. The results are consistent with recent suggestions that pattern masking does not terminate perceptual processing, but rather interferes with conscious awareness of completed visual analysis.
\end{abstract}

As a general rule, performance in perceptual and cognitive tasks is facilitated by advance information about upcoming stimuli, decisions, or responses (e.g., Haber, 1966; LaBerge, Peterson, \& Norden, 1977; Posner \& Snyder, 1975). An interesting exception to this rule, noted by Reicher (1969), is that foreknowledge of relevant alternatives actually may hamper identification of tachistoscopically presented single letters. Smith, Haviland, Reder, Brownell, and Adams (1976) found this "before-disruption effect" to occur for both forced-choice recognition (two alternatives) and same/different judgment (one alternative).

Smith et al. (1976) attributed the before-disruption effect to subjects' difficulty in discriminating between features of the target letter and features of the masking pattern typically used to limit visibility of the target. Precuing would lead subjects to erroneously extract anticipated features from the mask. In same/different judgment, foreknowledge of the alternative should then produce a preponderance of spurious "same" matches, which was found to be a concomitant effect of precuing.

Consistent with their hypothesis, Smith et al. (1976, Experiments 3 and 4 ) demonstrated that the before-disruption

I am indebted to Maria Blanco-Cruz, Brenda Buttram, Neil Folsom, Mark Fountain, Karen Kemp, Roy McAllister, Doreen Nicoff, Debbie Root, Alan Shaffren, Lee Solomon, Tom Studer, and John Walling for assistance in these and related experiments. Requests for reprints should be sent to W. Trammell Neill, Department of Psychology, University of South Florida, Tampa, FL 3362. effect depends on use of a pattern mask; when visibility was instead limited by reducing illumination of the target, the effect was not obtained. However, as noted by Neill and Walling (1981), other results of the Smith et al. (1976) study were less consistent with their account: In their Experiment 4, which required same/different matching, precuing actually caused a greater bias to respond "same" in the no-mask condition than in the mask condition. Furthermore, in their Experiment 5, which manipulated similarity between mask and stimulus features, similarity increased the same-bias effect of precuing, but actually decreased the before-disruption effect. Because Smith et al. attributed the two effects to the same underlying mechanism, one would expect them to be positively associated. In addition, mask features similar to the precued alternative should more likely be mistaken for those of the alternative, predicting an increase in the before-disruption effect with featural similarity.

Neill and Walling (1981) also found, across several experiments, a dissociation between the same-bias and before-disruption effects of precuing. In two experiments (Neill \& Walling, 1981, Experiments 1 and 2) procedurally similar to those of Smith et al. (1976), precuing produced sizable same-bias effects in the absence of any before-disruption effects. Particularly relevant to the present study are two experiments (Neill \& Walling, 1981, Experiments 3 and 4 ) in which featural similarity between paired alternatives was manipulated. In each experiment, one group received pairs differing in one critical feature ( $\mathrm{G}-\mathrm{C}, \mathrm{R}-\mathrm{P}, \mathrm{E}-\mathrm{F}, \mathrm{Q}-\mathrm{O})$ and another group received the 
same stimuli re-paired (G-P, E-O, R-C, Q-F). In both same/different judgments (Experiment 3 ) and forcedchoice judgments (Experiment 4), the before-disruption effect occurred only for featurally similar pairs. However, in same/different matching, precuing induced comparable same-bias effects for both similar and dissimilar pairings. The Smith et al. account also predicted that, for featurally similar pairs, precuing should increase errors specifically on targets lacking the critical distinguishing feature (i.e., importation of that feature from the mask would lead to correct responses on targets having that feature). No such effect was found. On the basis of these results, Neill and Walling (1981) concluded that the before-disruption effect reflected loss of relevant letter information rather than incorporation of irrelevant mask features into the target judgment.

Neill and Walling (1981) suggested that the beforedisruption effect may reflect differences in the level of processing at which the target is identified. Research by Posner (1969, 1978; Posner \& Mitchell, 1967) and others has demonstrated in speeded matching tasks that the physical representation of a letter can be distinguished from a more abstract representation, such as its name. For example, Posner and Mitchell (1967) found that physically identical letters (e.g., A-A) are matched more rapidly than letters identical in name only (e.g., A-a). Posner (1969, 1978) reviewed a body of evidence that the "physicalidentity" and "name-identity" levels may be differentially affected by a number of factors.

In the before-disruption effect, precuing with featurally similar alternatives may bias subjects to rely on the physical features, either because they attempt to detect the critical distinguishing feature, or perhaps because the similarity itself draws attention to that level of representation. Since the before-disruption effect seems dependent on the use of a pattern mask (Smith et al., 1976, Experiments 3 and 4 ), this processing strategy may be especially disrupted by such masking. On the other hand, when alternatives differ more globally, or are not known beforehand, subjects may tend to process the target more as a whole. This whole-letter processing may rely on a separate subsystem involving either naming or a more "abstract" visual classification (cf. Posner, 1969, 1978) which is less vulnerable to masking.

The levels-of-processing explanation predicts that the before-disruption effect should be eliminated if processing were constrained to the same level in the precued and unprecued conditions. This prediction was tested in the present Experiment 1 which required subjects to identify unfamiliar figures composed of letterlike features. Because such figures are presumably more difficult to name than familiar letters, subjects should be forced to rely more on the physical-identity level, in both the unprecued and the precued conditions. To the extent that processing occurs at the same level, one might hypothesize further that advance information appropriate to that level may facilitate processing, thereby reversing the before-disruption effect. $^{1}$
A further manipulation in Experiment 1 was to vary similarity between alternatives, parallel to the manipulation with letter stimuli by Neill and Walling (1981, Experiment 3). Whereas Neill and Walling found the beforedisruption effect specifically with similar alternatives, precuing with similar alternatives here should not influence the level of processing. Indeed, assuming that subjects must rely on an analysis of physical features in all conditions, foreknowledge of a particular critical feature might be advantageous, especially for confusable stimuli.

Similar reasoning underlies Experiment 2, which attempted to induce name-level processing in the precued as well as in the unprecued condition. Some subjects received letter targets that were unpredictably upper- or lowercase. Since a specific feature would no longer be sufficient to discriminate between alternatives, subjects would be forced to rely more on name-level categorization. Other subjects always received uppercase letter targets. It was predicted that precuing (with featurally similar alternatives) would disrupt performance only in this pure-case condition, in which a feature-testing strategy could be applied.

Experiment 3 was motivated by spontaneous reports by subjects in previous experiments that they were often able to confidently "guess" the target identity in the unprecued condition even though not phenomenally aware of seeing any target. In the precued condition, subjects reported more phenomenal awareness of the target, even though it may not have been "seen" clearly enough to discriminate between alternatives. If valid, such reports suggest that phenomenal awareness of the stimulus, which may depend on the physical-identity level, is not necessary for discrimination at higher levels, consistent with recent speculations by Marcel (1983a, 1983b; Marcel \& Patterson, 1978). In this experiment, no target was presented on certain trials, and subjects were required to make a presence/absence (detection) judgment as well as a forced-choice discrimination judgment between featurally similar alternatives. It was hypothesized that precuing would improve detection performance (by directing attention to the physical level) even though discrimination performance was disrupted. Furthermore, it was hypothesized that correct discrimination would be less dependent on conscious detection in the unprecued condition than in the precued condition.

\section{EXPERIMENT 1}

\section{Method}

Subjects. Each of 16 University of South Florida undergraduates participated in an individual 1-h session for course credit.

Stimuli and Apparatus. Stimuli were the figures shown in Figure 1, drawn individually in black ink on white cards using a Pickett 46VI Modern Bold inking template. The stimuli were presented by a Polymetric V-0959 two-channel tachistoscope with auxiliary Hunter Model 115 and 111-C timers. A stimulus subtended a visual angle of approximately $2.5^{\circ}$ vertically and $1.7^{\circ}$ horizontally.

Procedure. Eight subjects were randomly assigned to the "similar" group, for which stimulus alternatives differed in only one 
<smiles>[O]</smiles>
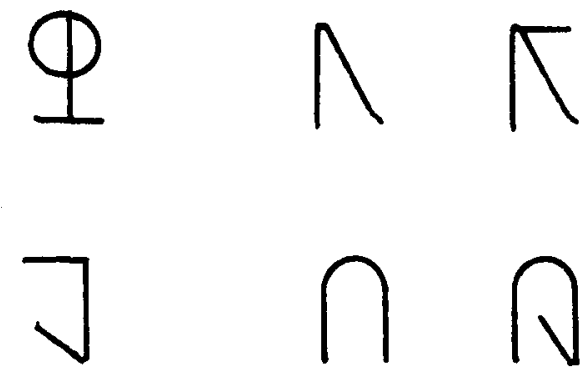

1

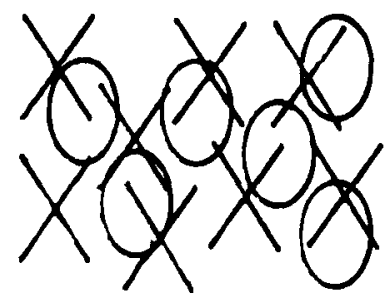

Figure 1. Stimuli and masking pattern used in Experiment 1.

critical feature. For the remaining 8 subjects, the stimuli were repaired to form four pairs of dissimilar stimulus alternatives.

In the precued condition, a trial began with the subject viewing a comparison stimulus on a card and hand-held by the experimenter. After acknowledging that the card had been viewed, the subject looked into the tachistoscope. The experimenter then announced "ready" and initiated an audible timer. At $1 \mathrm{sec}$ after initiation, the target stimulus was displayed in the center of the tachistoscope field for $40 \mathrm{msec}$, and then was immediately replaced by a masking pattern of superimposed Xs and Os lasting approximately 500 msec. $^{2}$ The subject then looked up from the tachistoscope to again view the comparison stimulus, to which the subject verbally responded "same" or "different" with respect to the target. No feedback was given to the subject about correctness of response. Procedure for unprecued trials was identical, except that the subject viewed a blank card rather than the comparison stimulus prior to looking in the tachistoscope.

Blocks of 24 precued trials were alternated with blocks of 24 unprecued trials, with half the subjects in each group beginning with a precue block and half with a no-precue block. Each subject received two practice blocks with a 140-msec target duration, followed by a total of six experimental blocks.

"Same" and "different" trials and choice of targets and comparison stimuli were randomly predetermined, with the constraint that each stimulus be used equally often as a comparison stimulus and as a target stimulus. For the target conditions, each stimulus was used equally often as a "same" target stimulus and as a "different" stimulus.

\section{Results}

Table 1 displays the mean percentages of correct "same" and "different" responses as a function of precuing and similarity conditions. Precued trials produced better performance $(78 \%)$ than did unprecued trials $(71 \%)$ $[\mathrm{F}(1,14)=8.96, \mathrm{p}<.01]$. Dissimilar alternatives produced better performance $(81 \%)$ than did similar alternatives $(68 \%)[\mathrm{F}(1,14)=17.97, \mathrm{p}<.01]$. More correct "same" responses $(77 \%)$ were made than "different" responses $(72 \%)[F(1,14)=10.13, p<.01]$.
Precuing interacted with both response and similarity. Precuing selectively enhanced "same" responses $(85 \%$ vs. $70 \%$ for unprecued alternatives), but did not affect "different" responses (72\% for both precued and unprecued alternatives) $[F(1,14)=16.77, p<.01]$. Precuing also selectively facilitated the similar-alternative group ( $76 \%$ vs. $60 \%$ for unprecued alternatives), but did not affect the dissimilar-alternative group $(81 \%$ for both types of alternative) $[F(1,14)=10.23, p<.01]$. No other interactions achieved significance.

To further explore discriminability and response-bias effects, these data also were converted to the Signal Detection Theory measures $\mathrm{d}^{\prime}$ and $\beta$, respectively (cf. Egan, 1975; Green \& Swets, 1966). Analysis of $d^{\prime}$ indicated that precuing facilitated discriminability overall $\left(\mathrm{d}^{\prime}=1.72\right.$ vs. 1.20 for unprecued alternatives) $[\mathrm{F}(1,14)=6.21, \mathrm{p}<$ .05.]. Performance also was better overall on dissimilar pairs $\left(\mathrm{d}^{\prime}=1.87\right)$ than on similar pairs $\left(\mathrm{d}^{\prime}=1.05\right),[\mathrm{F}(1,14)$ $=13.30, \mathrm{p}<.01]$. However, these two variables interacted significantly $[F(1,14)=6.00, p<.05]$. As shown in Table 1, precuing selectively facilitated similar pairings, having no effect on dissimilar pairings. Analysis of $\beta$ indicated that precuing induced a bias to respond "same" overall $(\beta=.69$ for precued, vs. 1.02 for unprecued alternatives $[\mathrm{F}(1,14)=14.90, \mathrm{p}<.01]$. However, there was neither an effect of pair similarity, nor any interaction. ${ }^{3}$

\section{Discussion}

These results stand in marked contrast to those of Neill and Walling (1981, Experiment 3) despite near identity of procedure. Neill and Walling found, using familiar letter stimuli, that precuing disrupted performance, particularly when alternative pairs were featurally similar. The present experiment, using letterlike but unfamiliar stimuli, found precuing to facilitate performance, especially when alternative pairs were featurally similar. This result is consistent with that found with pictorial stimuli (Egeth \& Smith, 1967). Contrary to Smith et al. (1976), the beforedisruption effect appears to depend on familiarity rather than on mere composition of letterlike features. This suggests that familiar letters provide the opportunity for recognition at a higher, more abstract level of processing, but foreknowledge of a single distinguishing feature

Table 1

Percentages of Correct "Same" and "Different" Responses, Discriminability, and Response Bias as Functions of Precuing and Similarity of Alternatives (Experiment 1)

\begin{tabular}{|c|c|c|c|c|c|}
\hline \multirow[b]{2}{*}{ Condition } & \multicolumn{2}{|c|}{ Response } & \multirow[b]{2}{*}{ Average } & \multirow[b]{2}{*}{$d^{\prime}$} & \multirow[b]{2}{*}{$\beta$} \\
\hline & Same & Different & & & \\
\hline \multicolumn{6}{|c|}{ Similar Alternatives } \\
\hline Precued & $83 \%$ & $68 \%$ & $76 \%$ & 1.56 & .72 \\
\hline Unprecued & $60 \%$ & $60 \%$ & $60 \%$ & .54 & .95 \\
\hline \multicolumn{6}{|c|}{ Dissimilar alternatives } \\
\hline Precued & $86 \%$ & $75 \%$ & $81 \%$ & 1.88 & .65 \\
\hline Unprecued & $79 \%$ & $83 \%$ & $81 \%$ & 1.87 & 1.08 \\
\hline
\end{tabular}

Note $-d^{\prime}=$ discriminability; $\beta=$ response bias. $\beta$ less than 1 indicates "same" bias. 
distracts subjects from using that information. Unfamiliar stimuli, however, must be distinguished at a featural level, and so foreknowledge of a critical feature is helpful rather than detrimental.

It may seem surprising that precuing had little effect (other than response bias) on dissimilar alternatives. However, for such stimuli, extraction of any target information has a high likelihood of discriminating between the alternatives. Because of this informational redundancy, there may be little advantage to directing attention to a particular feature.

A logically possible criticism of the present experiment is that there is no absolute guarantee of equating nonletters with letters on everything but familiarity. Thus, although the stimuli in Figure 1 are intuitively letterlike, and similar pairs differ in the same sort of features (vertical or diagonal line segment) as in Neill and Walling (1981), it is always possible that some configurational property did differ from letters. Experiment 2 therefore was performed to provide a different but convergent test of the levels-of-processing hypothesis.

\section{EXPERIMENT 2}

The levels-of-processing explanation for the beforedisruption effect attributes it to reliance on physical identity when precued with similar alternatives, but on name identity when unprecued or when precued with dissimilar alternatives. It was reasoned in Experiment 1 that use of unfamiliar stimuli would force reliance on physical identity in all conditions, thereby eliminating the beforedisruption effect. Similarly, it follows that encouraging reliance on name identity in all cue conditions should attenuate the effect. This hypothesis was tested by Neill (1979), with mixed results. In mixed-case blocks, targets were unpredictably either upper- or lowercase letters. The comparison stimuli were always uppercase letters. "Same" responses were required for both physicalidentity matches (e.g., A-A) and name-identity matches (e.g., A-a). In pure-case blocks, targets were always uppercase letters. It was predicted that increased uncertainty about the relevant features for a "same" match in the mixed-case blocks would encourage name-level processing even in the precued condition, thereby reducing the before-disruption effect. Unfortunately, no beforedisruption effect was found for either pure- or mixed-case blocks. In retrospect, the failure to find a before-disruption effect in the pure-case blocks was probably due to the fact that alternative pairs varied in featural similarity, subsequently found by Neill and Walling (1981) to mediate the before-disruption effect. Nevertheless, some support for the levels-of-processing hypothesis was found within the mixed-case data: lowercase, but not uppercase, targets were facilitated by precuing, despite the lesser featural similarity to the uppercase comparison stimuli.

The present Experiment 2 repeats this experiment, using stimulus pairs with an a priori likelihood of yielding before-disruption in a pure-case condition: G-C, E-F,
R-P, and Q-O (Neill \& Walling, 1981, Experiments 3 and 4). The present experiment also differed from Neill (1979) in manipulating pure-case versus mixed-case in a between-groups design, in order to maximize the likelihood of differing processing strategies in the two conditions.

\section{Method}

Subjects. Each of 20 University of South Florida undergraduates participated in an individual 1 -h session in exchange for extra credit in a psychology course.

Stimuli and apparatus. Comparison stimuli consisted of the capital letters C, G, F, E, O, Q, P, and R in Prestige Elite 10-pitch type (identical to that used by Neill \& Walling, 1981, Experiments 3 and 4). Target stimuli consisted of these letters and, in the mixedcase condition, their lowercase counterparts (also in Prestige Elite 10-pitch type). A capital letter subtended a visual angle of approximately $0^{\circ} 30^{\prime}$ vertically and $0^{\circ} 25^{\prime}$ horizontally. Apparatus were identical to those used in Experiment 1.

Procedure. Ten subjects were randomly assigned to the purecase condition, in which target stimuli were always uppercase. The remaining 10 subjects were assigned to the mixed-case condition, in which target stimuli were unpredictably either uppercase or lowercase.

"Different" targets were always the uppercase letter featurally similar to the comparison stimulus, or its lowercase counterpart (the latter only appearing in the mixed-case condition). In the mixedcase condition, target case was predetermined randomly and independently of whether a "same" or a "different" response was required

Each subject received two practice blocks of 24 trials, in which target duration was set at $160 \mathrm{msec}$, and then six experimental blocks of 24 trials each, with a target duration of $60 \mathrm{msec}$. As in Experiment 1 , blocks alternated between precued and unprecued conditions, with order counterbalanced across subjects.

All other aspects of procedure were identical to that used in Experiment 1 .

\section{Results}

Table 2 displays the mean percentages of correct "same" and "different" responses as a function of presentation (pure vs. mixed case), stimulus type (uppervs. lowercase), and precuing condition. Comparing uppercase targets in pure and mixed contexts, ANOVA revealed a significant main effect of precuing (73\% precued vs. $79 \%$ unprecued) $[\mathrm{F}(1,18)=29.30, \mathrm{p}<.01]$. In ad-

Table 2

Percentages of Correct "Same" and "Different" Responses, Discriminability, and Response Bias as Functions of Precuing Target Case, and Block Type (Experiment 2)

\begin{tabular}{lcccccc}
\hline & \multicolumn{2}{c}{ Response } & & & \\
\cline { 2 - 3 } Condition & Same & Different & Average & $\mathrm{d}^{\prime}$ & $\beta$ \\
\hline $\begin{array}{l}\text { Uppercase/Pure } \\
\text { Precued }\end{array}$ & $77 \%$ & $60 \%$ & $68 \%$ & 1.09 & .72 \\
$\quad$ Unprecued & $81 \%$ & $78 \%$ & $78 \%$ & 1.69 & .78 \\
$\begin{array}{l}\text { Uppercase/Mixed } \\
\quad \text { Precued }\end{array}$ & $86 \%$ & $68 \%$ & $77 \%$ & 1.64 & .56 \\
$\begin{array}{l}\text { Unprecued } \\
\text { Lowercase/Mixed }\end{array}$ & $83 \%$ & $79 \%$ & $81 \%$ & 1.79 & .82 \\
$\begin{array}{l}\text { Precued } \\
\text { Unprecued }\end{array}$ & $86 \%$ & $71 \%$ & $78 \%$ & 1.68 & .60 \\
\hline
\end{tabular}

Note $-d^{\prime}$ discriminability; $\beta=$ response bias. $\beta$ less than 1 indicates "same bias. 
dition, "same" trials were more accurate than "different" trials $(82 \%$ vs. $71 \%)[\mathrm{F}(1,18)=71.59, \mathrm{p}<.01]$.

Presentation context did not have a significant main effect; it did, however, interact with precuing $[F(1,18)=$ $6.42, \mathrm{p}<.05]$. As predicted, the before-disruption effect was greater in the pure-case context $(68 \%$ precued vs. $78 \%$ unprecued) than in the mixed-case context (77\% precued vs. $81 \%$ unprecued). Precuing also interacted with response $[F(1,18)=24.88, p<.01]$, reflecting the same-bias effect of precuing found in previous experiments. No other interactions were significant.

The Signal Detection Theory measure of discriminability $\left(d^{\prime}\right)$ was lower overall in the precued conditions $\left(d^{\prime}=1.37\right)$ than in the unprecued conditions $\left(d^{\prime}=1.74\right)$ $[\mathrm{F}(1,18)=18.63, \mathrm{p}<.01]$. In addition, precuing interacted with presentation context $[\mathrm{F}(1,18)=6.47, \mathrm{p}<$ .05]. As shown in Table 2, the before-disruption effect was particularly pronounced in the pure-case context. In contrast, the measure of response bias $(\beta)$ showed only an overall effect of precuing $[F(1,18)=5.09, p<.05]$, reflecting a greater same-bias in the precued conditions $(\beta=.63)$ than in the unprecued conditions $(\beta=.80)$.

Although no specific hypotheses were made about upper- versus lowercase targets within the mixed-case blocks, this data was also analyzed in a separate ANOVA. "Same" trials $(82 \%)$ were more accurate than "different" trials $(72 \%)[F(1,9)=39.89, p<.01]$. There were no significant main effects of case or precuing. Precuing did, however, interact with both responses $[\mathrm{F}(1,9)=$ $14.33, p<.01]$ and with case $[F(1,9)=6.97, p<.05]$. The former interaction reflects the typical same-bias effect of precuing. The latter interaction reflects a tendency toward a precuing facilitation for lowercase stimuli (78\% precued vs. $73 \%$ unprecued), opposite to that for uppercase stimuli (77\% precued vs. $81 \%$ unprecued).

The discriminability measure $\mathrm{d}^{\prime}$ yielded only a significant interaction of precuing with case $[\mathrm{F}(1,9)=5.82$, $\mathrm{p}<.05]$. As shown in Table 2, this again reflects the opposite directions of precuing effects on upper- and lowercase targets. The response bias measure $\beta$ yielded only a main effect of precuing $[F(1,9)=10.23, p<.02]$, again reflecting greater same-bias in the precued conditions $(\beta=.58)$ than in the unprecued conditions $(\beta=.88)$.

\section{Discussion}

The results of Experiment 2 show that the beforedisruption effect is attenuated when targets are unpredictably upper- or lowercase. Indeed, it seems paradoxical that in the precued conditions, performance is actually better when uncertainty about target features is increased (i.e., in mixed-case context). Together with Experiment 1 and the effects of similarity found by Neill and Walling (1981), these results converge on the conclusion that foreknowledge of a single critical feature hampers performance if attention is diverted to a more superficial, and under these conditions less efficient, level of processing.

Within the mixed-case condition, precuing interacted with target case. While uppercase targets showed a tendency toward before-disruption effect (albeit less than in the purecase condition), lowercase targets showed a tendency toward facilitation with precuing. A similar result was found by Neill (1979). It is not clear why lowercase targets should benefit more from precuing, especially since the comparison stimuli were always uppercase. It is not unlikely that subjects sometimes attended to the featural level despite the mixed-case context. However, whereas testing for particular physical features may be relatively inefficient for recognition of the uppercase targets, such a strategy would be even more deleterious to recognizing lowercase targets, which could not be discriminated on the basis of the features of the comparison stimulus. A tentative explanation is that use of all uppercase comparison stimuli may have increased the visual familiarity of uppercase targets much more than that of lowercase targets. The less familiar lowercase targets may therefore have had more opportunity to benefit from the facilitative effects of precuing, analogous to the results of Experiment 1. Whether use of lowercase comparison stimuli would reverse the interaction remains an empirical question; it is not, however, critical to the present conclusions. ${ }^{4}$

\section{EXPERIMENT 3}

Subjects in the study by Smith et al. (1976, p. 160) reported that they consciously searched for features in the precued conditions, but tried to perceive whole letters in the unprecued conditions. Such introspections are clearly in accord with the present empirical conclusions. Similar reports were offered by subjects in informal postexperiment interviews by Neill and Walling (1981). In addition, several subjects reported a surprising subjective phenomenon in the unprecued condition, subsequently verified phenomenally by the authors and experimenters: On some trials, there was no conscious awareness of having seen the target; rather, the field appeared blank, Yet, the name of a letter would seem to enter conscious awareness spontaneously, as if by the subject's own volition. This letter would then turn out to be one of the stimulus alternatives, giving rise to a feeling of "clairvoyance." In the precued condition, by contrast, subjects reported more awareness of having seen a target, although often not clearly enough for its identification.

If valid, the reports seem to indicate a form of "subliminal perception" (cf. Dixon, 1971) on some trials in the unprecued condition. This is of particular interest because it suggests that directing attention to a higher level of processing may reduce conscious awareness of the specific visual stimulation, while paradoxically yielding more accurate discrimination. This hypothesis was tested directly in Experiment 3 by requiring subjects to make a presence/absence detection judgment on each trial as well as a forced-choice discrimination judgment. It was predicted that the precued condition, although inferior in target discrimination, would yield better detection performance than the unprecued condition. In addition, it was hypothesized that on trials in which detection failed 
(i.e., incorrect "no" responses), target discrimination would be better in the unprecued condition than in the precued condition.

\section{Method}

Subjects. Each of 24 University of South Florida undergraduates participated in an individual $1-\mathrm{h}$ session in exchange for extra credit in a psychology course.

Stimuli and Apparatus. Stimuli consisted of the capital letters used in Experiment 2. Apparatus were identical to those used in previous experiments.

Procedure. In order to minimize confusion between the detection and discrimination tasks, the present experiment differed from Experiments 1 and 2 in requiring forced-choice discrimination rather than same/different judgment. Thus, subjects were always shown a pair of featurally similar alternatives, rather than a single comparison letter. Previous studies (Neill \& Walling, 1981; Smith et al., 1976) have found the two procedures to yield similar results (although forced-choice discrimination does not lend itself to analysis of response bias).

Each subject received two practice blocks of 24 trials each, with a target duration of $160 \mathrm{msec}$, and then six experimental blocks of 24 trials each, with a target duration of $60 \mathrm{msec}$. Blocks alternated between precued and unprecued conditions, with order counterbalanced across subjects. On 8 randomly selected trials in each block, the target field was blank for the exposure duration. Immediately after the masking pattern was seen, subjects were required to respond "yes" if they believed they had seen a target or "no" if they did not. Regardless of response, subjects then were shown the stimulus alternatives for a forced-choice judgment.

All other aspects of procedure were similar to those used in the previous experiments.

\section{Results}

The before-disruption effect was obtained: The probability of a correct target identification was higher in the unprecued condition (.71) than in the precued condition $(.64)[t(23)=2.33, p<.05]$. (All reported $t$ tests are two-tailed.) On the other hand, as predicted, the probability of detecting a target in the precued condition (.85) was higher than in the unprecued condition (.75) [ $\mathrm{t}(23)$ $=2.91, \mathrm{p}<.01]$. This latter result does not reflect simply a difference in response bias, since the probability of a false alarm on nontarget trials was essentially the same for the precued condition and the unprecued condition (both .24).

Further analysis examined identification responses conditionalized on type of detection response. On trials in which overt target detection occurred (correct "yes" responses), the probability of correct target identification was higher in the unprecued condition $(.75)$ than in the precued condition $(.67)[t(23)=2.49, \mathrm{p}<.05]$. On trials in which overt target detection failed to occur (incorrect "no"' responses), the probability of correct target identification was again higher in the unprecued condition (.58) than in the precued condition $(.49)[\mathrm{t}(23)=2.20$, $\mathrm{p}<.05]$. The probability in the unprecued condition (.58) was also greater than chance $(.50)[\mathrm{t}(23)=2.52$, $\mathrm{p}<.02$, whereas the probability in the precued condition (.49) obviously was not.

\section{Discussion}

The before-disruption effect was replicated here in forced-choice identification, similar to Smith et al. (1976, Experiments 1 and 3) and Neill and Walling (1981, Experiment 4). This experiment reveals that superior target identification in the unprecued condition is paradoxically associated with less conscious awareness of the visual stimulus, as indicated by overt detection of target presence. In the precued condition, target identification was strictly dependent on target detection, as reflected in identification at chance level on trials in which target detection failed. In the unprecued condition, however, identification on nondetection trials showed a small but significant improvement over chance.

In the context of the previous experiments, this result suggests that directing attention to the visual features of a target enhances conscious detection of the target, that is, awareness of the visual stimulus. This may, however, result in less awareness of target identity. Conversely, attending to a more abstract level of processing may increase the availability of information about target identity, but reduce certainty about the actual presence of a visual stimulus.

It is certainly not the case that identification occurred independently of detection in the unprecued condition. Indeed, the probability of correct identification was much higher on trials in which target detection occurred. There are undoubtedly numerous variables that would have correlated effects on both detection and identification (e.g., transient changes in sensitivity due to eye movement, accommodation, alertness, stimulus characteristics, etc.). In addition, it seems likely that subjects would discover that a seemingly spontaneous impression of a letter name in the absence of a visual impression was often predictive of the subsequent alternatives. Even though no feedback was given to subjects about correctness of response, a subject could infer that a target must have been presented. Thus, within a condition we should expect that target identification is positively related to target detection even if not strictly dependent on it.

\section{GENERAL DISCUSSION}

Neill and Walling (1981) suggested that when letter targets are precued with featurally similar alternatives, subjects may adopt a relatively inefficient strategy of searching for a critical distinguishing feature. When not precued, or when precued with alternatives differing more globally, subjects may instead rely on a more abstract representation of the target, such as its name. In other words, the before-disruption effect is attributed to a difference in "level of processing" in precued and unprecued conditions, analogous to the difference between "physicalidentity" and "name-identity" levels implicated in speeded matching tasks (e.g., Posner, 1969). This predicts that the before-disruption effect should be attenuated if 
subjects are encouraged to process at the same level in precued and unprecued conditions.

Experiments 1 and 2 confirm the prediction of the levels-of-processing hypothesis. In Experiment 1, subjects were forced to process at the physical-identity level regardless of cuing condition, because the stimuli were unfamiliar and hence less nameable than familiar letters. It was found here that precuing facilitated, rather than disrupted, identification, particularly when stimulus alternatives differed in one critical feature--exactly opposite to the pattern found with familiar letters (Neill \& Walling, 1981, Experiments 3 and 4). Thus, contrary to Smith et al. (1976), composition of letterlike features is not in itself sufficient to produce the before-disruption effect. In the mixed-case condition of Experiment 2, subjects were induced to process target letters at the name-identity level regardless of cuing condition because of increased uncertainty regarding critical target features. Only in the pure-case condition, in which critical features were predictable from the precue, was the before-disruption effect found.

That processing at the name level may provide more accurate identification than processing at the physical level is supported by the "word-superiority effect," in which imbedding in a word enhances letter identification (Reicher, 1969; Wheeler, 1970). Mezrich (1973) eliminated the advantage of words over single letters by requiring subjects to pronounce the target name, thereby presumably forcing equivalent levels of processing. Similarly, Hawkins, Reicher, Rogers, and Peterson (1976) found no word superiority for letters whose alternatives unexpectedly formed homophones (e.g., SENT-CENT), implying that subjects relied on phonological coding to discriminate between predominantly nonhomophonic alternatives (e.g., SOLD-COLD) which were superior to single letters. (When homophones occurred often, they showed an effect comparable to nonhomophones, suggesting that another level, perhaps semantic, may also facilitate identification.) Especially pertinent to the beforedisruption effect is the finding that the word-superiority effect also depends on the use of a pattern mask to limit target visibility (Johnston \& McClelland, 1973). Thus, it appears that the disadvantage of processing information only at the physical level lies in specific vulnerability to pattern masking.

Experiment 3 found that superior letter identification in the unprecued condition was paradoxically associated with less conscious awareness of the stimulus, as indicated by overt target detection. It would appear that attention to the more "superficial" level of processing, induced by precuing, enhances awareness of the visual stimulus per se, despite the relative inefficiency of target identification. (Verbalized detection is not intended here as either a necessary or sufficient condition for inferring conscious awareness of the stimulus. Rather, it is only assumed that conscious awareness and verbalizability are positively correlated. It seems unlikely that subjects were more conscious of the visual stimulus in the unprecued condition, and yet less able to verbalize its presence.)

Marcel (1983a, 1983b; Marcel \& Patterson, 1978) has proposed that conscious awareness of a stimulus depends on a "record" of the visual analysis, which is essentially independent of further processing at deeper levels. Pattern masking interferes with access of this record to consciousness; it does not, however, prevent phonemic or semantic analysis (see also Fowler, Wolford, Slade, \& Tassinary, 1981). In contrast, energy masking, which is presumed to operate at a more peripheral level than pattern masking (Turvey, 1973), seems to limit the information available to both the visual record and the deeper levels of processing. Similarly, the dependence of the before-disruption effect on pattern masking would appear to reflect the continued availability of name-level information in the unprecued condition. If target visibility is instead limited by reduced luminance level (Smith et al., 1976, Experiments 3 and 4), insufficient activation may occur at the name level, and more advantage may be gained by foreknowledge of physical features.

Marcel's theory leads to the present speculation that the strategy of testing for a critical feature, induced by precuing with similar alternatives, likewise depends on the record of visual analysis. Interference from the pattern mask makes this strategy inefficient. On the other hand, attention to the impoverished visual record will still result in more conscious awareness of the visual stimulus than if attention is directed to a more abstract level. An unanswered question is whether directing attention to a particular level actually enhances the quality of information at that level, or whether it only serves to utilize information already activated at that level while it is still available; that is, when attention is directed to the visual record, does activation still occur at the naming level which is simply not noticed, or does the activation of name information actually depend on attention's being directed to the corresponding level?

The before-disruption effect, which may have previously seemed just an unexplained curiosity in the literature, now appears relevant to a number of current issues, including the effects on perceptual analysis of masking, context, familiarity, and attention and the relation of perceptual analysis to conscious awareness. But perhaps the most important aspect of the before-disruption effect is the fact that it occurs at all. Although common sense seems to dictate that advance information, if veridical, should always be helpful, the before-disruption effect reminds us that preparation may fail if it directs attention to an inappropriate level of processing. In other words, "forewarned" is not always "forearmed."

\section{REFERENCES}

Dixon, N. F. (1971). Subliminal perception: The nature of a controversy. New York: McGraw-Hill.

Egan, J. P. (1975). Signal detection theory and ROC analysis. New York: Academic Press. 
Egeth, H. E., \& SMrTh, E. E. (1967). Perceptual selectivity in a visual recognition task. Journal of Experimental Psychology, 74, 534-549.

Fowler, C. A., Wolford, G., Slade, R., \& Tassinary, L. (1981). Lexical access with and without awareness. Journal of Experimental Psychology: General, 110, 341-362.

Green, D. M., \& Swets, J. A. (1966). Signal detection theory and psychophysics. New York: Wiley.

HABER, R. N. (1966). Nature of the effect of set on perception. Psychological Review, 73, 335-351.

Hawkins, H. L., Reicher, G. M., Rogers, M., \& Peterson, L. (1976). Flexible coding in word recognition. Journal of Experimental Psychology: Human Perception \& Performance, 2, 380-385.

Johnston, J. C. , \& McClelLaND, J. L. (1973). Visual factors in word perception. Perception \& Psychophysics, 14, 365-370.

LaBerge, D., Peterson, R. J., \& Norden, M. J. (1977). Exploring the limits of cuing. In S. Dornic (Ed.), Attention and performance $V I$ (pp. 285-306). Hillsdale, NJ: Erlbaum.

Marcel, A. J. (1983a). Conscious and unconscious perception: An approach to the relations between phenomenal experience and perceptual processes. Cognitive Psychology, 15, 283-300.

MarCEL, A. J. (1983b). Conscious and unconscious perception: Experiments on visual masking and word recognition. Cognitive Psychology, 15, 197-237.

Marcel, A. J., \& Patterson, K. E. (1978). Word recognition and production: Reciprocity in clinical and normal studies. In J. Requin (Ed.), Attention and performance VII (pp. 209-226). Hillsdale, NJ: Erlbaum.

Mezrich, J. J. (1973). The word familiarity effect in brief displays: Elimination by vocalization. Perception \& Psychophysics, 13, 45-48.

NeILl, W. T. (1979, March). Disruptive effects of prior information on tachistoscopic recognition? Paper presented to the meeting of the Southeastern Psychological Association, New Orleans, LA.

NeILl, W. T., \& WALling, J. R. (1981). Disruptive effects of prior information on tachistoscopic recognition. Memory \& Cognition, 9 , 217-224.

PoSNer, M. I. (1969). Abstraction and the process of recognition. In G. H. Bower \& J. T. Spence (Eds.), Psychology of learning and motivation: Vol. 3 (pp. 43-100). New York: Academic Press.

PoSNER, M. I. (1978). Chronometric explorations of mind. Hillsdale, NJ: Erlbaum.

Posner, M. I., \& Mrtchell, R. F. (1967). Chronometric analysis of classification. Psychological Review, 74, 392-409.

Posner, M. I., \& SNyder, C. R. R. (1975). Attention and cognitive control. In R. S. Solso (Ed.), Information processing and cognition: The Loyola symposium (pp. 55-85). Hillsdale, NI: Erlbaum.

Reicher, G. M. (1969). Perceptual recognition as a function of meaning fulness of stimulus material. Journal of Experimental Psychology, $\mathbf{8 1}$, 275-280.

Smith, E. E., Haviland, S. E., Reder, L. M., Brownell, H., \& ADAMS, N. (1976). When preparation fails: Disruptive effects of prior information on perceptual recognition. Journal of Experimental Psychology: Human Perception \& Performance, 2, 151-161.

TURVEY, M. T. (1973). On peripheral and central processes in vision:
Inferences from an information-processing analysis of masking with patterned stimuli. Psychological Review, 80, 1-52.

WheEler, D. D. (1970). Processes in word recognition. Cognitive Psychology, 1, 59-85.

\section{NOTES}

1. Smith et al. (1976, p. 155) informally reported such a study, using novel patterns constructed from the same features as letters. Although they did not describe the experiment in detail, they reported the mean percentages of correct "same" and "different" responses for the two conditions: In the precued condition, 98\% correct "sames" and $65 \%$ correct "differents"; in the unprecued condition, $88 \%$ correct "sames" and $86 \%$ correct "differents." Since the overall percentage correct in the precued condition $(81 \%)$ was significantly less than in the unprecued condition $(87 \%)$, Smith et al. concluded that the before-disruption effect was not dependent on visual familiarity. However, this conclusion overlooks the fact that extreme response bias can cause overall percentage correct to underestimate true discriminability. For example, converting the reported "same" and "different" percentages into the Signal Detection Theory measure d' (Egan, 1975; Green \& Swets, 1966), we find $\mathrm{d}^{\prime}=2.44$ in the precued condition and $\mathrm{d}^{\prime}=2.26$ in the unprecued condition, reversing the direction of the difference. Especially since the correct "sames" in the precued condition (98\%) are so near ceiling, these data must be viewed as equivocal.

2. Probably because of greater size and contrast, a shorter target duration than that used by Neill and Walling (1981) was necessary to avoid ceiling effects on performance. A small pilot study $(n=6)$ using featurally similar letter alternatives determined these display parameters to be sufficient for before-disnuption with familiar stimuli.

3. The analysis of $\beta$ was actually performed on logarithmically transformed $\beta$ scores for each individual, to increase homogeneity of variance. The likelihood ratio $\beta$ ranges between 0 and 1 for positive response bias (here defined as "same" response) and between 1 and $\infty$ for negative ("different") bias. However, $\log \beta$ is symmetrical about 0 for positive and negative biases (see Egan, 1975). It should also be noted that the independence of $\mathrm{d}^{\prime}$ and $\beta$ depends on particular distributional assumptions (normality and equal variance for noise and signal+noise distributions), which are not always justified (see Egan, 1975). However, insofar as the measures here confirm the patterns apparent in the raw percentages, it is not likely that violation of these assumptions poses any problem for interpretation of the data.

4. Ideally, comparison-stimuli letter case would be varied in the same manner as target case in the same experiment. However, given that similarity between alternatives affects before-disruption (Neill \& Walling, 1981), the practical problem arises of creating letter pairs for which uppercase and lowercase versions are equivalent in featural similarity. The present design therefore restricts conclusions to context effects on identification of uppercase targets.

(Manuscript received November 19, 1984; revision accepted for publication August 2, 1985.) 